\title{
Photovoltaics in Spanish Deserts: Evaluation of the Technology Potential and Costs
}

\author{
Rafael Peña \\ Departamento de Electrónica y Comunicaciones \\ Universidad Europea de Madrid \\ Rio Tajo S/N, 28670, Villaviciosa de Odón-Madrid. \\ Phone: +34912115652, Fax: +34916168265, E-mail: rafael.pena@uem.es
}

\begin{abstract}
The potential of large photovoltaic (PV) plants, particularly of those based on concentrator systems, is really high. In Spain, where $18 \%$ of land is affected by severe desertification, this technology could significantly contribute to the total electric demand in just a few years. The availability of large stretches of abandoned lands with a very high level of irradiation, the technological progress in concentrator systems and the cost reduction in PV technology caused by experience in production are the main reasons for this great potential.

In this work, 3 technical scenarios are considered in order to evaluate the capacity of very large PV plants for mass electricity production. For every scenario, the power to install, the land surface needed and the cost reduction expected with large PV plants are calculated. A proposal for a selected scenario is also included. Both conventional flat panel and concentrator systems are considered in this analysis.
\end{abstract}

The results show that, with concentrator PV systems, the whole electricity demand in Spain could be provided using less than 3 $\%$ of the total surface of arid lands in the country. The price of the systems could be significantly lower than that of conventional flat panel installations, lower than $0.5 € / \mathrm{W}$ for cumulative power of $10 \mathrm{GW}$.

\section{Key words}

Large scale photovoltaics, solar energy in deserts, costs, concentration, learning curves

\section{Introduction}

According to the United Nations Program for Human Settlements [1] a $44 \%$ of the land surface of Spain is affected by desertification. This phenomenon is especially important in the $18 \%$ of the total surface, about 9.000.000 HA, which is affected by severe or very severe desertification. These areas are placed in the south of Spain, in the Mediterranean provinces and also in Aragón and other inner areas of the country.

Apart from arid places, there are a lot lands in Spain which are also been abandoned for any use. For instance, agricultural syndicates estimate that, in last decade, 2 million hectares have been abandoned for dry agriculture in the country, a $10 \%$ of the total surface devoted to this activity.

An important feature of many of these places, particularly in arid areas, is that they have a very high level of irradiation: Murcia 1805, Granada 1673, Almería 1713 in $\mathrm{kWh} / \mathrm{m}^{2} /$ year (horizontal). The average irradiation in the country is $1526 \mathrm{kWh} / \mathrm{m}^{2} /$ year. In fact, these data correspond to the province capital, thus the irradiation in deserted areas in those provinces being higher, up to $1750-1900 \mathrm{kwh} / \mathrm{m}^{2} /$ year.

Therefore, their potential for mass photovoltaic electricity production is really large. It has been estimated that using $4 \%$ of desert areas in the world the whole electrical energy consumption could be supplied [2]. In this sense, PV plants in the range 50-150 MW have been proposed this year, and the first installations are beginning to be built right now. The most representative examples are those projected in Moura (62 MW), Portugal, and Victoria (154 MW), Australia. They will be finished in 2010 and 2013, respectively.

\section{Interest of the work}

As far as the author knows, there is no published work which thoroughly evaluates the possibilities of very large scale photovoltaics in Spanish deserts. Just in reference [2] there is a brief assessment about this topic. Particularly, there is no work which considers the potential of concentrator PV systems based on III-V compound semiconductor multi-junction solar cells for electricity production in these areas. These cells, manufactured using GaAs and other related semiconductors [3], allow very high efficiencies, over 40 $\%$ [4]. Besides, concentrator systems are the most promising approach in order to achieve cost competitive PV plants.

Consequently, the purpose of this work is to assess the potential of PV systems for the particular conditions in Spanish arid areas. The assessment includes the evaluation of the surface needed in order to supply a significant fraction of Spanish electrical consumption, the study of the different technical scenarios s in order to setup the PV plants and of the different cost scenarios.

\section{Scenarios for implementation of large PV plants in deserts}

In order to evaluate the potential of large scale PV in arid areas, 3 scenarios have been considered (table I). They are representative of the expected evolution of $\mathrm{PV}$ technologies.

a. Short term scenario: it considers solar plants based on high efficiency crystalline silicon modules, commercially available at present, in static arrays 
placed in optimum orientation and tilt. The module efficiency has been fixed to $18 \%$, the highest value for a real commercial module today. This efficiency will be typical in a 5 to 10 year period. A performance ratio (PR) of 0.7 and a space factor (SF) of 0.3 have been assumed, achievable in current PV plants with a right design.

b. Midterm scenario: Solar plants based on high efficiency concentrator modules with current III-V compound multi-junction solar cells, on 2-axis trackers. The efficiency has been fixed to $25 \%$, a real value for modules which are in an early stage of commercialization right now [4]. $\mathrm{PR}=0.75$ and $\mathrm{SF}=0.2$ have been assumed. The lower SF has been chosen due to the higher shadowing losses in 2-axis tracking systems.

c. Long term scenario: Solar plants based on high efficiency concentrator modules with III-V compound multi-junction solar cells, on 2-axis trackers. The module efficiency has been fixed to $33 \%$. This high value is envisaged to be achieved in a 15 year period. $\mathrm{PR}=0.8$ and $\mathrm{SF}=0.2$ have been assumed. The higher value for PR has been chosen in order to consider future improvements in BOS components.

In all the scenarios, the space factor is defined as the ratio between the total surface of the PV modules and the whole PV plant surface.

\section{Evaluation of the power to install and the land requirements for large PV plants}

The average energy production for a PV plant in a year, $E$, can be calculated as follows [5]:

$$
E=P \cdot\left(\frac{G_{y}}{G}\right) \cdot F S \cdot P R
$$

Being $P$ the plant nominal power, $G_{y}$ the average annual irradiation on the module surface, $F S$ a factor considering the shadowing losses and $P R$ the system performance ratio. $G$ is the solar illumination in standard conditions, i.e., $1 \mathrm{~kW} / \mathrm{m}^{2}$. $G_{y}$ must consider the real illumination on the module surface, which depends on the module tilt and orientation and their dirtiness conditions.
In order to obtain a given energy production, and for a certain solar irradiation, the PV plant power can be calculated from (1). In order to do this, the system performance ratio must be selected from table I, for each scenario.

For a given power to install, the surface occupied by the PV plant can be obtained from the efficiency of the PV modules, taking into account the surface factor considered for every scenario.

The results presented below assume no shadowing losses $(F S=1)$, which is possible in large plants with the conservative space factors considered in this work (between 0.2 and 0.3 ). Optimum orientation and tilt and a medium dirtiness degree (which is characterized by transmission losses in the normal direction of about $3 \%$ ) are also assumed [5]. For scenario 1, an annual horizontal irradiation $G_{y}=1800 \mathrm{kWh} / \mathrm{m}^{2}$ has been assumed. For scenarios 2 and 3, direct irradiation has been considered (since they correspond to 2-axis concentrator systems), with $G_{y}=2000 \mathrm{kWh} / \mathrm{m}^{2}$. These values are possible in desert areas in Spain, the object of this work.

Table II shows the surface needed in order to supply the whole electricity consumed in Spain in 2005 as well as the power to install for the 3 scenarios. In all the cases, a surface smaller than $0.8 \%$ of the whole Spanish area is needed. This value corresponds to less than $4 \%$ of the surface of arid areas in the country. The installed PV power is between 168 and $195 \mathrm{GW}$, being lower for long term scenario (as expected).

Table II: total PV power to install in order to supply the whole Spanish electrical demand in 2005, for every scenario. The surface occupied by the PV plants is also shown, as a percentage of the surface of Spanish arid areas and of the whole Spanish surface.

\begin{tabular}{|c|c|c|c|}
\hline Scenario & $P(G W)$ & Arid Surface & Spanish Surface \\
\hline Short Term & 195 & $4.01 \%$ & $0.72 \%$ \\
\hline Midterm & 173 & $3.97 \%$ & $0.71 \%$ \\
\hline Long Term & 168 & $2.82 \%$ & $0.50 \%$ \\
\hline
\end{tabular}

Table I: Scenarios considered in order to evaluate the potential of large PV plants in Spanish deserts

\begin{tabular}{|l|c|c|c|}
\cline { 2 - 4 } \multicolumn{1}{c|}{} & Short Term Scenario & Midterm Scenario & Long Term Scenario \\
\hline Module Efficiency & $18 \%$ & $25 \%$ & $33 \%$ \\
\hline Performance Ratio & 0.7 & 0.75 & 0.8 \\
\hline Space Factor & 0.3 & 0.2 & $\begin{array}{c}\text { Ultra high efficiency } \\
\text { Main Features }\end{array}$ \\
\hline $\begin{array}{c}\text { High efficiency crystalline } \\
\text { silicon modules in } \\
\text { conventional PV plants with } \\
\text { optimum orientation and tilt }\end{array}$ & $\begin{array}{c}\text { High efficiency concentrator } \\
\text { modules based on current III-V } \\
\text { compound multi-junction solar } \\
\text { cells, on 2-axis trackers }\end{array}$ & $\begin{array}{c}\text { concentrator modules based on } \\
\text { multi-junction solar cells, on 2- } \\
\text { axis trackers }\end{array}$ \\
\hline
\end{tabular}


The influence of the module efficiency and the irradiation in the plant location is shown in Figure 1, for the long term scenario. It depicts the PV plant surface in order to supply the whole electricity consumed in Spain. A surface smaller than $0.83 \%$ the whole Spanish area is needed in all these cases (even in those with a lower efficiency and irradiation). This value corresponds to less than $4.7 \%$ of the surface of arid areas in Spain. The red rectangle limits the obtained values for efficiency higher than $33 \%$ and direct irradiation higher than $2000 \mathrm{kWh} / \mathrm{m}^{2} /$ year.

\section{Proposal for the long term scenario}

Let us consider the long term scenario. Assuming a direct annual irradiation of $2000 \mathrm{kwh} / \mathrm{m}^{2}$ for the PV plants locations, the power to install in order to cover a $100 \%$ of the total Spanish electric demand in 2005 is about 168 GW (as shown above). Consequently, for a production of $10 \%$ of Spanish consumption, about $16.8 \mathrm{GW}$ should be installed, which could be done in a surface of about 253 $\mathrm{km}^{2}$. This area is smaller than $3 \%$ of the total surface of Almeria, one of the most deserted provinces in the country (or to $0.28 \%$ of the total Spanish arid areas, as shown above).

The PV power could be obtained by means of 100 plants with a unitary power of $168 \mathrm{MW}$, which consequently would occupy about $2.53 \mathrm{~km}^{2}$. With the assumptions in this long term scenario (efficiency $=0.33, \quad P R=0.8$, $\mathrm{SF}=0.2$ ), the actual energy productivity in every plant would be about 1550 hours a year.
It must be kept in mind that such a large facilities are right now being projected in Australia (the plant in Victoria will have $154 \mathrm{MW}$ ), using concentrator PV modules, just like in this long term scenario. The installations could be constructed in several stages, due to the modularity of PV systems, and their power increased gradually, as new energy needs arose. This is the approach followed in both the plant in Australia and in that in Moura, Portugal (62 MW).

The PV plants could be mainly distributed in the provinces of Alicante, Valencia, Murcia and in Andalucía and Aragon, in areas seriously affected by desertification. Moreover, in most of these provinces the electricity demand is greatly growing (especially in Levante), due to the new building developments and the increase in the use of air-conditioning. Beside, some of these places are close to other densely populated regions, such as Cataluña.

In fact, these large PV plants could be installed in many other places in Spain, also affected by desertification (Extremadura, Castilla la Mancha, Castilla y León, etc), in which the availability of large lands is not a problem, and the generated power could help to mitigate the sharp demand growth in close areas, such as in Madrid.

An important advantage of this approach is the ability of $\mathrm{PV}$ power to efficiently guarantee the coverage of demand in the moments of maximum consumption in summer, since the hours in which solar plants receive the maximum irradiation are close to the hottest ones, those in which the need for air-conditioning is maximum.

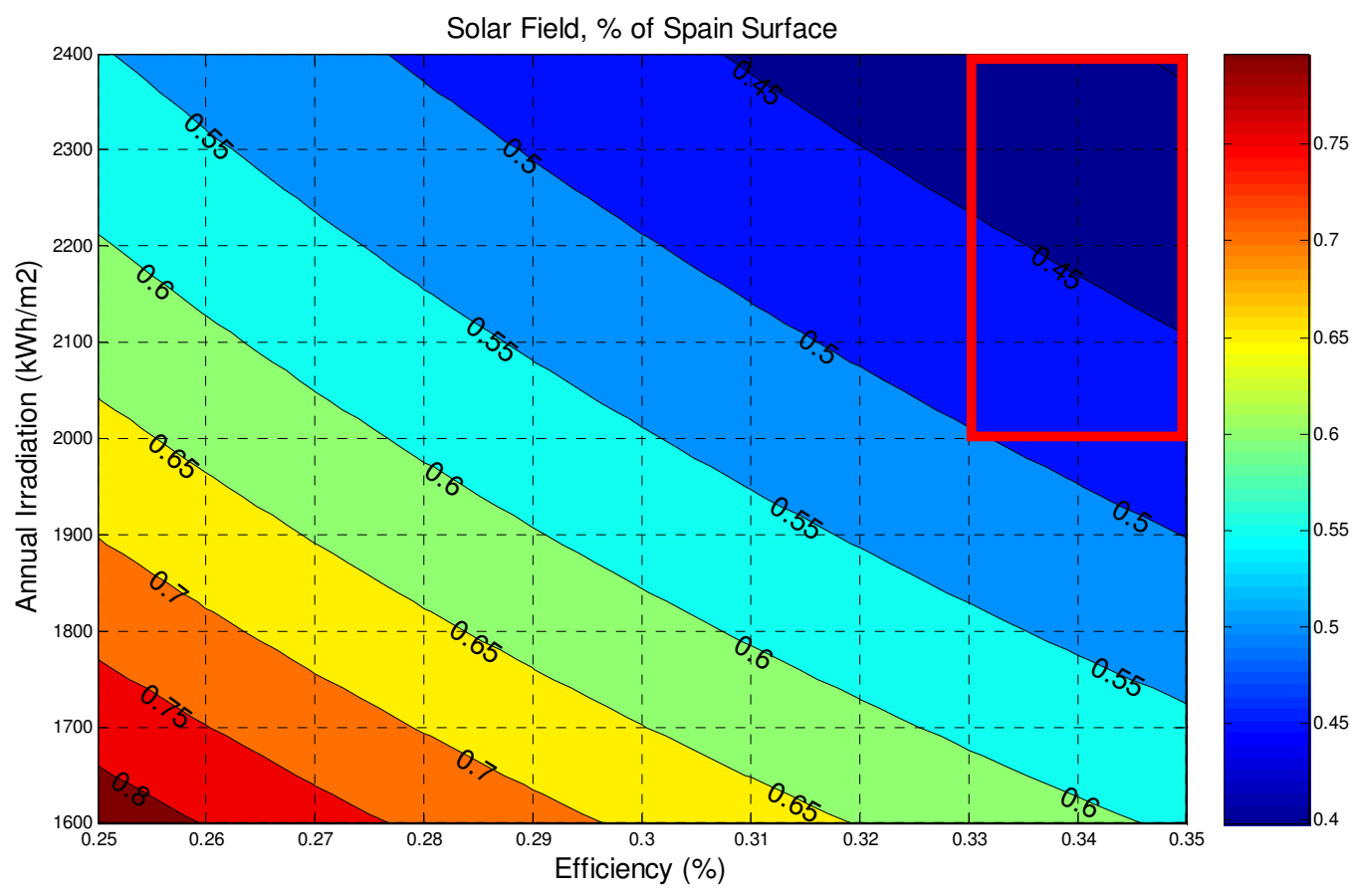

Figure 1: surface needed in order to supply the whole electricity consumed in Spain as a function of the irradiation and the efficiency of the installed PV modules. For $P R=0.8$ and $S F=0.2$ (long term scenario). 
An important aspect to consider when dealing with large $\mathrm{PV}$ plants is their connection to medium and longdistance power lines. In Spain, the planning for the electricity and gas sectors includes the construction of new high-voltage lines and the reinforcement of the most congested ones just in Andalucía, Aragón, Cataluña and Levante, the locations for the proposed large plants in this work.

\section{Cost analysis for the scenarios}

An experience curve approach is used here in order to evaluate the system price for the different presented scenarios [6]. PV modules price, $C$, can be calculated as a function of cumulative production, $q$, as follows:

$$
C=C_{0}\left(\frac{q}{q_{0}}\right)^{-b}
$$

Where $q_{0}$ and $C_{0}$ are the production and price values at a given initial time. Parameter $b$ is called "learning coefficient", and is obtained empirically. It characterizes the velocity at which PV technology evolves due to the accumulation of experience in production (including the improvement in all the production processes), leading to a price reduction. Rather than the learning coefficient, learning rate, $L R$, is commonly used in order to characterize the learning process:

$$
L R=1-2^{-b}
$$

$L R$ is the price reduction after doubling the cumulative produced capacity.

\subsection{Price for the short term scenario}

For the short term scenario, $L R$ is well known, since PV modules price has been registered for 30 years. $L R=0.2$ is generally assumed for this period, though it is increasing to values closer to $25 \%$ in last years. The influence of the price of balance of systems (BOS) components is rather constant over time, and it can be roughly estimated as about one third of the total cost for large plants [7].

Figure 2 depicts the calculated price of PV modules for the short term scenario as a function of $L R$ and the cumulative production. $L R$ has been changed between 0.15 and 0.25 , and cumulative production up to $2000 \mathrm{GW}$ has been considered. The modules price calculated for $L R=0.2$ is lower than $1 € / \mathrm{W}$ for cumulative production over $40 \mathrm{GW}$, which could happen before 2013, according to current market research. However, in order to estimate the system price for a particular scenario, some assumptions must be made about the cumulative production at the time of the plants implementation.

Currently the total PV power in Spain is about $60 \mathrm{MW}$, while the overall power in the World is higher than $5 \mathrm{GW}$ $[8,9]$. Therefore, the installed power in the country is slightly higher than $1 \%$ of the total PV capacity. This proportion is rising every year, since the PV market growth is much stronger in Spain than in the rest of the World. In this sense, the Spanish PV Industry Association (ASIF) forecasts a sharp increase in the installed power up to $1000 \mathrm{MW}(1 \mathrm{GW})$ by 2010 . The European PV industry Association (EPIA) forecasts 22 GW installed in the World by the end of that year [9]. Consequently, the proportion of installed PV power in Spain would increase to $4.4 \%$ of the total capacity.

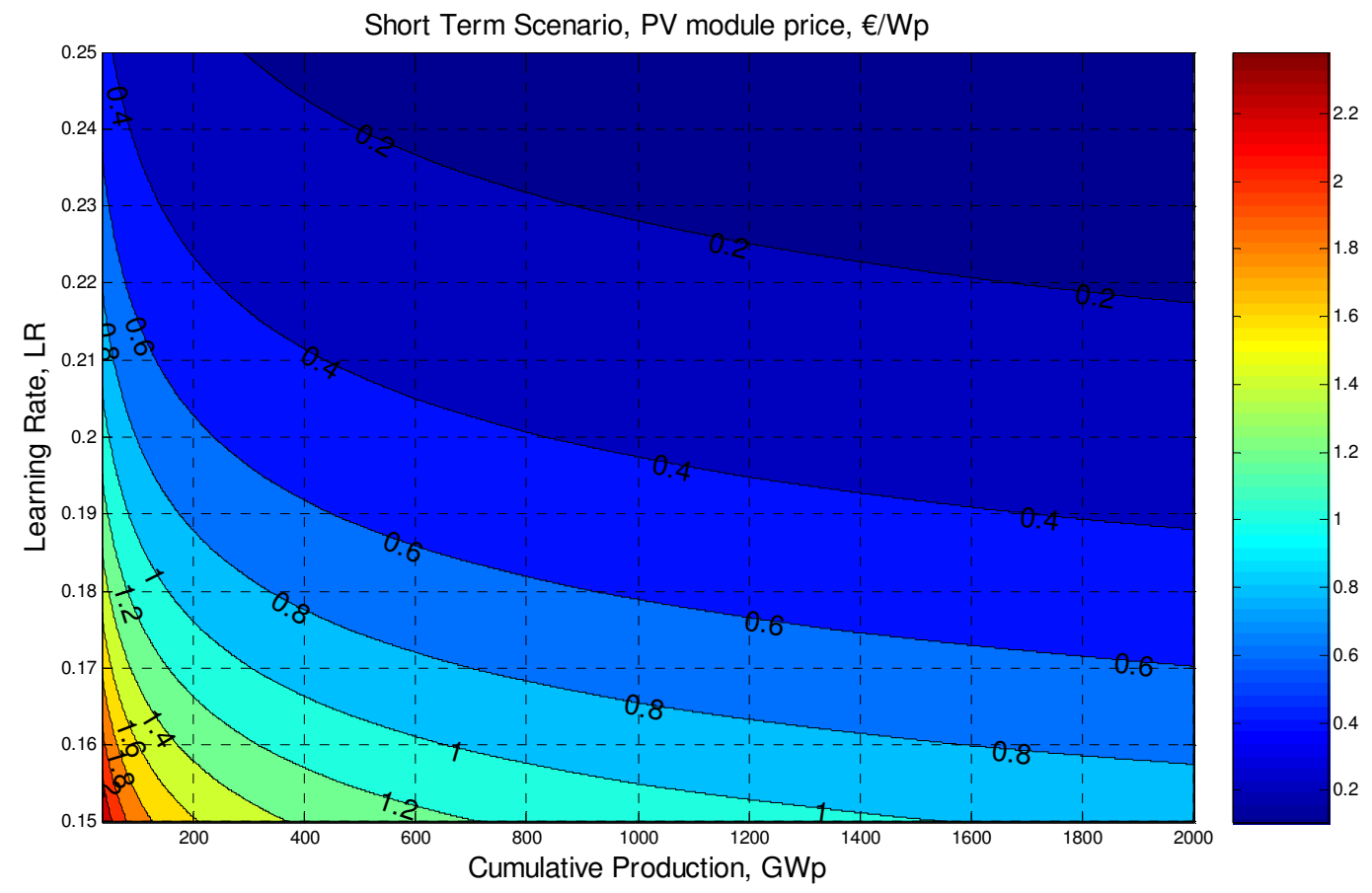

Figure 2: price of PV modules for flat panel systems (short term scenario) as a function of $L R$ and the cumulative production. 
For a total installed PV power of $19.5 \mathrm{GW}$ (in order to cover $10 \%$ of actual electricity demand with the assumptions of short term scenario), the installed power in the World would range between 390 and $1950 \mathrm{GW}$, for a Spanish PV proportion between 1 and $5 \%$. In the first case, the PV module price would be about $0.5 € / \mathrm{W}$, for $L R=0.2$ (see figure 2). In the last one, the price would be as low as $0.3 € / \mathrm{W}$.

The total price in this scenario should consider the influence of BOS. By adding $1 / 3$ of the PV module price (as discussed above), the final price would rise to 0.67 and $0.4 € / \mathrm{W}$, respectively.

\subsection{Price for mid and long term scenarios}

The learning coefficient for concentrator PV modules has just been estimated by some authors, since no empirical data are available about cumulative production in such a novel technology. The price of the modules and the tracking system for concentrator plants has been calculated in about $2.6 € / \mathrm{W}$ with current technology. In these systems, BOS costs about $19 \%$ of the total price, or roughly one fifth [4].

However, the potential cost reduction for concentrator systems (those considered in mid and long term scenarios) is significantly higher than for conventional flat modules technology. This can be seen in figure 3 , in which the price of PV modules and tracking is depicted as a function of $L R$ and the cumulative production.

For $L R=0.2$ (similar to that measured for flat panel technologies), with a cumulative production of just 10
$\mathrm{GW}$, a price of $0.35 € / \mathrm{W}$ could be obtained. The total price including an additional $20 \%$ for BOS components [4] would be as low as $0.42 € / \mathrm{W}$. This value, which is more than 10 times lower than the current price of large PV plants, shows the great potential for cost reduction of large concentrator photovoltaics, which could, in a few years, be cost competitive with conventional technologies based on fossil fuels.

\section{Conclusions}

Large scale PV plants can become a massive energy technology in next decades, particularly in Spanish arid areas. In these places, characterized by their very high levels of irradiation, concentrator technologies have the potential to provide a significant fraction of the whole electricity demand in the country at competitive prices.

In the long term scenario considered here, which could be technologically feasible in 15 years, a $10 \%$ of the total Spanish electric consumption could be supplied by these systems. In order to do this, just $0.28 \%$ of the Spanish arid lads would be occupied. The price of the systems could be significantly lower than that of current conventional flat panel installations, lower than $0.5 € / \mathrm{W}$ for cumulative power of $10 \mathrm{GW}$.

\section{Acknowledgement}

This work has been carried out within the frame of the project $\mathrm{H}_{2}$ elios.2006.01.

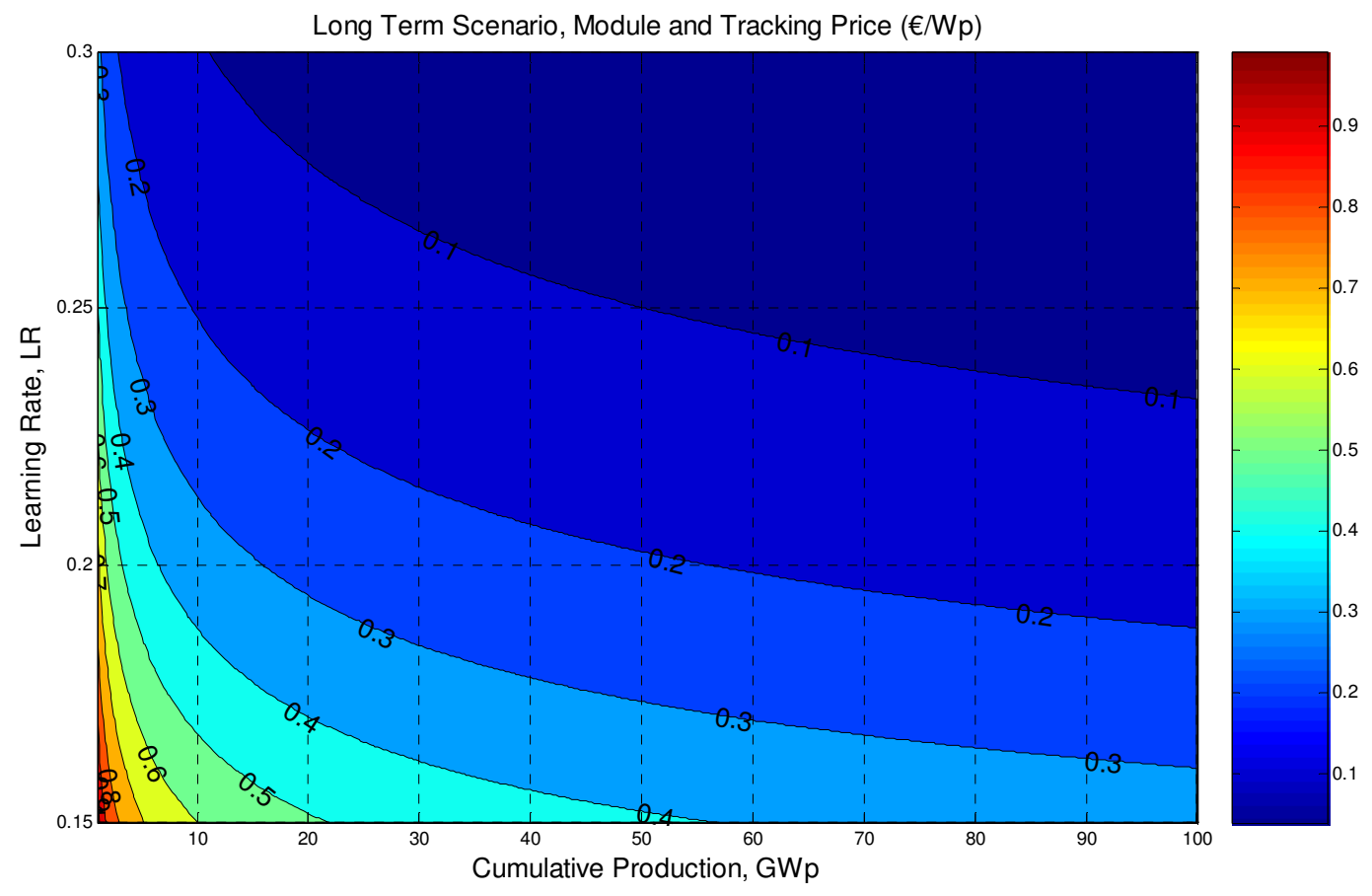

Figure 3: price of PV modules and tracking for concentrator systems (mid and long term scenarios) as a function of $L R$ and the cumulative production. 


\section{References}

[1] United Nations Program for Human Settlements, www.un.org/esa/agenda21/natlinfo/ countr/spain/SpainHS.pdf.

[2] K. Kurokawa (editor), "Energy from the desert", Earthscan, London, 2006.

[3] R. Peña, C. Algora, "The Influence of Monolithic Series Connection on the Efficiency of GaAs Photovoltaic Converters for Monochromatic Illumination", IEEE Trans. On Elec. Devices, 48, pp. 196-203 (2001).

[4] J. Luther et al, "Concentration Photovoltaics for Highest Efficiencies and Cost Reduction", 20 ${ }^{\text {th }}$ European PV Solar Energy Conference, Barcelona, Spain, pp. 1953-1957, 2005.

[5] E. Lorenzo, "La Energía que Producen los Sistemas Fotovoltaicos Conectados a la Red", Era Solar, 107, pp 22-28, 2002.

[6] G.F. Nemet, "Technical Change in Photovoltaics and the Applicability of the Learning Curve Model", Interim report 05029, International Institute for Applied Systems Analysis, 2005. [7] G.J. Schaeffer, H.H.C. de Moor, "Learning in PV: Trends and Future Prospects", $19^{\text {th }}$ European PV Solar Energy Conference, Paris, France, 2004.

[8] Asociación Solar de la Industria Fotovoltaica, ASIF, "Informe ASIF: Hacia una Generación Eléctrica Competitiva", 2006.

[9] K. Mc Donald (editor), "Solar Generation - Solar Electricity for over One Billion People and Two Million Jobs by 2020", Greenpeace - European Photovoltaic Industry Association report, 2006. 